\title{
Evasão e persistência em ações educacionais a distância: análise do perfil discente
}

Dropping out and persistence in distance education actions: analysis of the student profile Deserción y persistencia en la educación a distancia: análisis del perfil del estudiante

» Elienay Eiko Rodrigues UMEKAWA ${ }^{1}$ (Universidade de São Paulo)

» Thaís ZERBINI² (Universidade de São Paulo)

Resumo Pesquisas em avaliação de cursos a distância ainda são escassas. Este trabalho visa contribuir com a área ao propor e testar um modelo de avaliação de ações educacionais ofertadas a distância. $\mathrm{O}$ objetivo do estudo é analisar o relacionamento entre variáveis historicamente ligadas à evasão, à persistência acadêmica e às características da clientela, focalizando especialmente as estratégias de aprendizagem empregadas. Realizou-se a aplicação das seguintes escalas, as quais foram submetidas a validação estatística: Estratégias de aprendizagem e Fatores relacionados à evasão e à persistência em EaD. A coleta de dados foi realizada em três momentos distintos, e foram realizadas análises exploratórias fatoriais (Principal Components e Principal Axis Factoring) e de consistência interna (Alpha de Cronbach). A fim de cumprir o objetivo proposto, foi realizada a análise de regressão múltipla padrão. Os resultados indicaram a relevância do uso de estratégias que promovam o autogerenciamento dos processos de ensino e aprendizagem, a autorregulação da motivação/ansiedade e a busca por ajuda interpessoal na consecução de resultados acadêmicos positivos, beneficiando o desempenho dos discentes que estudam a distância.

Palavras-chave:

Educação a distância; evasão; educação

\section{Abstract}

Reviews of research in distance education courses are still scarce. This work aims to contribute to the field by proposing and testing a model for evaluating educational activities offered on-line. The objective of the study is to examine relationships between variables linked to dropping out, completing academic courses, and client characteristics, especially focusing on the learning strategies employed. The following scales were applied, subjected to statistical validation: learning strategies and factors related to dropouts and completions in distance education. Data collection was performed at three distinct points. Exploratory factor analyses (Principal Components and Principal Axis Factoring), and internal consistency analyses (Cronbach's alpha), were performed. To fulfill the proposed objective, a standard multiple regression analysis was performed. The results indicated the importance of using strategies that promote self-management processes of teaching and learning, self-regulation of motivation/anxiety and the search for interpersonal help in achieving positive academic outcomes, benefiting the performance of students who study on-line.

Keywords:

Distance education; dropout; education

1 Endereço: Rua Dr. Loyola, 864. Vila Tibério. CEP: 14050070. Ribeirão Preto, SP - Brasil. Telefone: (16) 36255219/(16) 992920453. Email: elienay@usp.br.

2 Universidade de São Paulo, Faculdade de Filosofia Ciências e Letras de Ribeirão Preto, Departamento de Psicologia e Educação. Avenida Bandeirantes, 3900, Bloco 3, Monte Alegre. CEP:14040901. Ribeirão Preto, SP - Brasil. Telefone: (16) 36024687. 
Investigaciones sobre de la evaluación de cursos a distancia aún son escasas. Este trabajo pretende contribuir con el área al proponer y poner a prueba un modelo de evaluación de las actividades de educación a distancia. El objetivo del estudio es analizar la relación entre variables históricamente asociadas a la deserción escolar, la persistencia y las características de los clientes, con especial énfasis en las estrategias de aprendizaje empleadas. Se aplicaron las siguientes escalas, las cuales fueron sometidas a una validación estadística previa: Estrategias de aprendizaje y Factores relacionados a la deserción escolar y la persistencia en EaD. La colecta de datos se realizó en tres momentos distintos y fueron realizados análisis factoriales (método de componentes principales y Principal Axis Factoring) y de consistencia interna (Alpha de Cronbach). Para lograr el objetivo propuesto, se realizó un análisis de regresión múltiple. Los resultados indicaron la importancia del uso de estrategias que promuevan la auto-gestión del proceso de enseñanza y aprendizaje, la auto-regulación de la motivación/ansiedad y la búsqueda por ayuda interpersonal en la consecución de resultados académicos positivos, beneficiando el rendimiento de los alumnos que estudian a distancia.

Palabras-clave:

Educación a distancia; deserción; educación.

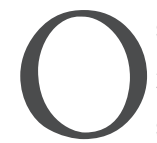
$s$ atuais contextos de trabalho e estudo enfrentam modificações de ordens diversas, como alterações nos recursos tecnológicos disponíveis, no sistema legal vigente e no processo de veiculação e processamento de informações. É verificada a presença de uma nova lógica de aprendizado e utilização de ferramentas diversificadas, e, frente a isso, ações de Treinamento, Desenvolvimento e Educação (TD\&E) passaram a gozar de incontestável relevância, uma vez que instrumentalizam indivíduos e organizações com conhecimentos, habilidades e atitudes necessários à sobrevivência e à diferenciação profissional e organizacional. Assim, adequados investimentos em ações de TD\&E se revelam como relevantes elementos de diferenciação competitiva, dada a existência de um mercado altamente volátil, no qual competências e instrumentos atingem a obsolescência em tempo mínimo (Meneses, Zerbini, \& Abbad, 2010).

Tais mudanças nos panoramas socioeconômicos e tecnológicos exigem medidas igualmente inovadoras capazes de responder às demandas e lacunas educacionais geradas. Nesse sentido, a educação a distância (EaD) está sendo considerada como dispositivo apropriado a tal cenário. Apesar das potencialidades inerentes à modalidade de ensino a distância, essa seara enfrenta diversos problemas. Um dos obstáculos mais relevantes e preocupantes observados corresponde aos elevados índices de abandono acadêmico. Diante dessa conjuntura, este artigo intenta avaliar possíveis relações entre variáveis que figuram entre as mais comumente associadas a evasão/persistência acadêmica na $\mathrm{EaD}$ e características da clientela, ou seja, as estratégias de aprendizagem utilizadas pelos discentes ao longo dos eventos instrucionais.

\section{Educação a distância}

Ações desenvolvidas no campo de TD\&E destacam-se em termos de relevância e necessidade, dado que os novos contextos de ensino e trabalho reclamam por iniciativas aptas a sanar lacunas de competências e que promovam sua constante atualização visando o bom desempenho acadêmico e profissional. Cada vez mais indivíduos e organizações laborais recorrem aos benefícios advindos das ações instrucionais que se refletem em incrementos financeiros, ocupacionais e de mercado; aquisição de conhecimentos; aprendizagem efetiva; otimização de desempenhos; e produtividade (Iglesias \& Salgado, 2012; Meneses et al., 2010).

Estratégias instrucionais diferenciadas estão sendo empregadas nos processos de ensino e aprendizagem, de modo que a expansão e o aprimoramento da área da tecnologia da informação e comunicação (TIC) contribuiu muito para tal condição. Considerando-se as transformações sofridas pelo campo de TD\&E, o ensino não presencial é compreendido como um recurso ajustado a tal contexto renovador. Dispositivo estratégico nessa nova realidade instrucional, a $\mathrm{EaD}$, ao recorrer às avançadas mídias digitais e ferramentas de interação, vem possibilitando que um contingente cada vez maior de indivíduos não só tenha acesso a conteúdos e informações, mas estabeleça contato, apesar de possíveis distanciamentos físicos.

A modalidade de ensino a distância vem sendo empregada desde a educação básica até o ensino superior, passando também por programas de ensino não tradicionais, como cursos de caráter aberto (Alves, 2011). Tal multiplicidade de uso deve-se à efetividade de tais ações que não difere daquela encontrada em eventos educacionais presenciais; ou seja, quando corretamente delineada e implementada, a EaD pode produzir resultados análogos à educação presencial (Iglesias \& Salgado, 2012). 
O crescimento que a educação a distância vem experimentando nas últimas décadas em solo nacional é vertiginoso: segundo o censo realizado pela Associação Brasileira de Educação a Distância [ABED] (2012) durante o ano de 2009, o número total de indivíduos cursando algum tipo de programa instrucional não presencial atingiu a marca de 2.597 .357 alunos. Apesar do crescente interesse pelos cursos ofertados a distância e do reconhecimento dos seus benefícios e vantagens, ainda restam graves hiatos na produção e sistematização dos conhecimentos da área, de forma que análises e discussões que versem sobre ações educacionais a distância se fazem necessárias (Carvalho \& Abbad, 2006; Castro \& Ferreira, 2006).

\section{Características da clientela}

É possível verificar a importância das características internas dos indivíduos que aprendem, seus hábitos pessoais, expectativas, motivações, interesses e objetivos para a obtenção de competências durante a ação educacional e no uso ulterior de tais capacidades em situações de trabalho (Meneses, Abbad, Zerbini, \& Lacerda, 2006). Segundo esses autores, o fenômeno da aquisição e transferência de novos conhecimentos e habilidades é possível a todos os indivíduos, entretanto, elementos como as condições de apoio à aprendizagem e à transferência e o desenho da ação instrucional devem concorrer para tal alteração de comportamento.

Assim, torna-se fundamental que medidas de características da clientela sejam consideradas ao se proceder o planejamento e a avaliação de necessidades de ações instrucionais em cenários laborais e de estudo.

De acordo com Zerbini e Abbad (2010), as características individuais podem exercer uma interferência mais significativa nos resultados de ações educacionais a distância do que naqueles de natureza presencial, uma vez que a aprendizagem efetiva está, nesse primeiro caso, subordinada muito mais ao empenho empreendido pelo próprio sujeito (autogerenciamento da aprendizagem) do que aos recursos educacionais disponíveis. Possivelmente, tais estratégias se diferem significativamente daquelas encontradas nas ações presenciais. Segundo Zerbini (2007), o planejamento instrucional de cursos não presenciais pode ser beneficiado pelo estudo das estratégias de aprendizagem utilizadas pelos discentes e das características apresentadas por eles. Achados advindos de investigações de tal ordem podem apurar o delineamento e a excelência de tais programas de ensino.

Estratégias de aprendizagem são conceitualizadas como a tomada cônscia/proposital de deliberações ajustadas às condições do contexto em que um evento educacional ocorre e constante em relação ao acionamento de conteúdos de natureza distinta para obtenção dos objetivos de aprendizagem almejados (Badia \& Monereo, 2010). Segundo o sistema classificatório proposto por Warr e Allan (1998), as estratégias poderiam ser dispostas em três grandes categorias, as quais compreendem distintos níveis de análise: 1) Estratégias cognitivas (primárias); 2) Estratégias comportamentais (primárias); e 3) Estratégias autorregulatórias. As duas primeiras atuam sobre os processos de escolha, processamento, retenção e recuperação de informações, sendo utilizadas na situação de contato do aprendiz com os conteúdos a serem transmitidos. Já as autorregulatórias dizem respeito à motivação da pessoa para aprender, à autogestão de esforços, ao automonitoramento do progresso durante a aprendizagem e ao controle da ansiedade frente a determinadas situações que estariam dissipando a atenção do aprendiz.

O refinamento de informações referentes à clientela possibilita identificar o perfil dos sujeitos frequentadores de programas de ensino distintos e conhecer quais tipos de estratégias eles empregam para atingir a aprendizagem, ofertando elementos para aprimorar as modalidades educacionais de acordo com as suas características e necessidades pessoais. Consequentemente, evita-se a inadequada consideração de dados acerca da personalidade, do nível de inteligência e da motivação em cenários de organizações (Zerbini, 2007). Ademais, a compreensão acerca das estratégias de aprendizagem pode ser de grande valia para aperfeiçoar o planejamento instrucional de ações a distância, uma vez que favorecem o reconhecimento dos processos individuais de aprendizagem utilizados e dos procedimentos instrucionais mais adequados a cada agente envolvido (Zerbini, 2007; Zerbini \& Abbad, 2010).

\section{Fatores relacionados à evasão e à persistência discente}

Apesar das potencialidades e vantagens inerentes à modalidade de ensino a distância, esse campo responde a diversos desafios e obstáculos. Talvez uma das mais perniciosas problemáticas existentes sejam os elevados índices de abandono acadêmico observados nesse contexto educacional (Sales, 2009). Certamente, a questão da desistência e retenção discente é conceitualizada como o elemento de relevância mais expressiva para o êxito 
da EaD. Enfrentando o chamado déficit da educação a distância, o ensino não presencial revela preocupantes índices de conclusão correspondentes a 25\%, ou menos, dos obtidos pela educação presencial (Simpson, 2013).

No tocante às razões que levam o aluno a não concluir um programa de ensino a distância, a literatura indica uma multiplicidade de fatores que correspondem tanto a variáveis internas à própria ação instrucional como a elementos externos a ela. Aspectos relativos à elevada complexidade da vida pessoal, laboral, financeira e familiar figuram entre os inúmeros motivos relacionados à desistência e ao insucesso estudantil. Também se torna essencial considerar a influência exercida pelas instituições de ensino responsáveis pela oferta de cursos a distância e as políticas sociais mal implementadas, que, com frequência, não satisfazendo as necessidades dos discentes, os deixam evadir, sem, contudo, demonstrar interesse em reconhecer os fatores causais e desenvolver medidas que os contenham (Siqueira, 2009). Algumas das variáveis historicamente ligadas ao abandono discente em iniciativas de $\mathrm{EaD}$ podem ser classificadas em três grandes grupos (Abbad, 2007; Sales, 2009; Xenos, Pierrakeas, \& Pintelas, 2002): (1) fatores relativos ao evento instrucional; (2) fatores relacionados a características pessoais dos estudantes; e (3) fatores ligados ao contexto que cerca o aluno a distância.

Em relação às variáveis do curso ligadas à evasão, a literatura aponta que problemas correlatos ao desempenho do tutor, como questões do exercício profissional, falta de apoio ao aluno, falta de conhecimentos ou inabilidade para transmiti-los, são descritos como uma das causas para o abandono discente (Abreu-e-Lima \& Alves, 2011; Lee \& Anderson, 2013). Os elementos ligados mais intimamente ao desenho instrucional, tal como os procedimentos instrucionais adotados e aqueles relativos ao ambiente virtual de aprendizagem, à natureza do evento educacional e ao apoio psicossocial prestado aos estudantes, também são tidos como fatores medulares que contribuem para a desistência do curso (França, 2009; Silva \& Tomaz, 2006; Wang, FoucarSzocki, Grinffin, O’Connor, \& Sceiford, 2003; Oliveira \& Tedesco, 2010).

Entre as características do aluno que influenciam o abandono de cursos em EaD encontram-se a falta de habilidades do estudante de fazer uso das ferramentas eletrônicas disponibilizadas, a inabilidade de organizar o tempo de estudo e a autodisciplina (Deimann \& Bastiaens, 2010; Romero \& Barberà, 2011). Pesquisas indicam que indivíduos que experimentam maiores dificuldades em relação ao manejo dos instrumentais eletrônicos do curso possuem maiores chances de evadirem-se dos programas educacionais (Almeida, 2007; Silva $\&$ Tomaz, 2006).

Por fim, as variáveis do contexto de estudo do aprendiz ligadas à ocorrência da evasão figuram como muito importantes, uma vez que a $\mathrm{EaD}$ não só admite maior flexibilidade de horários e locais de estudo, bem como expõe o estudante a uma gama mais elevada e complexa de estímulos. Segundo Sales (2009), tais variáveis se relacionam à adequação do ambiente familiar, do trabalho e a outras questões que envolvem a vida do aluno e que podem interferir em seus processos formativos. A exemplo, a escassez de tempo para dedicar-se aos estudos se configura como um dos principais fatores da desistência discente em cursos a distância (Almeida, 2007; Pacheco, Rissi, Nakayama, Silveira, \& Spanhol, 2010; Yukselturk \& Inan, 2006). Condições precárias de estudo no lar, pressões domésticas, enfermidades e questões relativas ao trabalho são sugeridas como possíveis indicadores de evasão (Almeida, 2007; Vargas, 2004).

Estudos empíricos na área ainda são pouco extensos e conclusivos, de modo que é justificável a realização de investigações que se proponham a avaliar os elementos ligados à ocorrência de evasão. Segundo Ngoma, Simwanza e Makukna (2004), o campo de estudos de EaD ainda não conta com um número satisfatório de modelos teóricos de suficiente validade preditiva para os fenômenos que se fazem presentes e afetam tal cenário. Assim, fica clara a necessidade de desenvolvimento de novos trabalhos que não só se detenham no entendimento de variáveis relacionadas à evasão em $\mathrm{EaD}$, mas que proponham modelos teóricos para avaliação dessa modalidade de ensino.

\section{MÉTODO}

\section{Participantes}

A pesquisa compreendeu a avaliação de distintas ações educacionais de nível superior ofertadas por três instituições educacionais de caráter público e privado situadas na região de Ribeirão Preto (SP). Em tais estabelecimentos de ensino são oferecidos cursos de graduação e especialização que têm o objetivo de fomentar a preparação de recursos humanos altamente qualificados que, consequentemente, concorrerão para o desenvol- 
vimento da coletividade. A população do estudo consistiu no número de inscritos em tais ações instrucionais no período de 29 de novembro de 2012 a 04 de agosto de 2013, totalizando 126 alunos.

Foram enviados questionários de Estratégias de Aprendizagem e Fatores Relacionados à Evasão e à Persistência em $\mathrm{EaD}$ a todos os inscritos nas instituições partícipes no período anteriormente mencionado. No tocante às características sociodemográficas da população, verificou-se que a amostra é composta predominantemente por indivíduos do sexo masculino $(50,8 \%)$, casados $(63,3 \%)$, com filhos $(56,6 \%)$ e residentes na região Sudeste (84,3\%). Em média, a amostra considerada possui 36,5 anos de idade (DP = 8,53), sendo 32 anos a idade declarada com mais frequência, 58 anos a idade máxima e 19 anos a mínima. No tocante à formação educacional, a maior parcela de participantes declarou contar com o ensino superior completo $(61,2 \%)$ e, majoritariamente, todos os respondentes relataram possuir experiência prévia no uso da internet, denotando domínio das ferramentas e instrumentais utilizados nos ambientes virtuais. Vale ressaltar que a maior parcela dos respondentes $(43,8 \%)$ declararam contar com uma renda financeira de mais de sete salários mínimos.

A elevada heterogeneidade perpassou as respostas dos participantes referentes à ocupação/profissão exercida, sendo tais dados classificados a partir de cinco grandes categorias de atuação laboral, a saber: Humanas (pedagogia, relações públicas, publicidade, direito); Exatas e Tecnologia (engenharia, estatística, contabilidade); Gestão e Negócios (administração, coordenação financeira, gerência); Comércio e Autônomo (vendedor, bancário, representante comercial); e outros. Na última categoria proposta, foram inclusas atividades que não se encaixaram nos demais campos, como trabalhos temporários e de natureza informal, bem como aquelas relativas ao trabalho em casa (donas de casa) e ao estudo (estudantes). A maior parte da amostra relatou exercer atribuições ligadas ao comércio ou de caráter autônomo $(28,3 \%)$. Todavia, o desempenho de funções pertinentes a gestão e negócios também figurou como expressivo (27,4\%).

\section{Instrumentos}

Os instrumentos de medida utilizados são: 1) Questionário Sociodemográfico - refere-se aos dados demográficos dos participantes, como sexo, idade, região geográfica, composição familiar, renda, estado civil, nível de escolaridade e experiência prévia com a internet; 2) Estratégias de Aprendizagem - revalidado por Martins (2012) e que apresentou 31 itens e 4 fatores com cargas fatoriais variando de $-0,69$ a 0,76. Os itens dessa ferramenta foram associados a uma escala de frequência de comportamento de 11 pontos que varia de 0 (Nunca) a 10 (Sempre); 3) Fatores Relacionados à Evasão e à Persistência em EaD - adaptado e revalidado por Umekawa (2014) e que apresentou 45 itens e 4 fatores com cargas fatoriais variando de $-0,64$ a 0,93. Os itens do questionário foram associados a uma escala de avaliação de 11 pontos que variaram de -5 (dificultou muito) $\mathrm{a}+5$ (facilitou muito), com ponto médio 0 (não dificultou nem facilitou). Informações sobre os instrumentos, como descrição de fatores e exemplificação de itens, se encontram na Tabela 1.

TABELA 1. Resumo das informações sobre o instrumento utilizado na pesquisa

\begin{tabular}{|c|c|c|c|}
\hline Instrumento & Escalas obtidas & $\mathrm{N}^{\circ}$ itens & $\begin{array}{l}\text { Exemplos } \\
\text { de itens }\end{array}$ \\
\hline \multirow{4}{*}{$\begin{array}{l}\text { Estratégias de } \\
\text { Aprendizagem }\end{array}$} & Monitoramento da compreensão & 14 & $\begin{array}{l}\text { "Elaborei perguntas para testar minha compreensão sobre } \\
\text { os conteúdos do curso." }\end{array}$ \\
\hline & Estratégias autorregulatórias & 9 & "Mantive a calma quando tive dificuldades." \\
\hline & Busca de ajuda interpessoal & 4 & $\begin{array}{l}\text { "Busquei auxílio de colegas nos fóruns para esclarecer } \\
\text { minhas dúvidas." }\end{array}$ \\
\hline & $\begin{array}{l}\text { Estratégias cognitivo- } \\
\text { comportamentais }\end{array}$ & 10 & "Fiz anotações sobre o conteúdo do curso." \\
\hline \multirow{4}{*}{$\begin{array}{l}\text { Fatores Relacionados } \\
\text { à Evasão e à } \\
\text { Persistência em EAD }\end{array}$} & Suporte tecnológico e de tutoria & 18 & $\begin{array}{l}\text { "O apoio fornecido pelo tutor à interação entre os } \\
\text { participantes do curso." }\end{array}$ \\
\hline & Características exógenas ao curso & 11 & "Meu tempo disponível para realização do curso." \\
\hline & Características do aluno & 8 & $\begin{array}{l}\text { "Minha habilidade em administrar o tempo para me dedicar } \\
\text { aos estudos." }\end{array}$ \\
\hline & Desenho do curso & 4 & "O grau de complexidade do curso." \\
\hline
\end{tabular}

\section{Procedimentos}

As ferramentas foram hospedadas em uma página da internet para a coleta eletrônica de dados, e as instruções de preenchimento dos questionários foram enviadas por e-mail no último dia dos cursos. Foram disponibilizados, no ambiente virtual de aprendizagem, banners que explicitavam os procedimentos da pesquisa e 
solicitava ao participante o preenchimento dos instrumentos, cujo endereço eletrônico estava indicado em um link específico. As respostas aos questionários foram digitalizadas e integradas ao banco de dados. Assim que o processo de coleta de dados foi finalizado e uma amostra estatisticamente significativa foi obtida, as informações foram enviadas ao SPSS (Statistical Package for the Social Science) versão 16.0, software que viabilizou as análises do material coletado.

Foram efetuadas análises descritivas e exploratórias a fim de examinar a exatidão da entrada dos dados, a presença de casos extremos, a distribuição dos casos omissos, a distribuição de frequência e o tamanho das amostras, segundo orientações de Tabachnick e Fidell (2001). Em seguida, deu-se início à validação estatística dos instrumentos. Para a extração inicial dos fatores, realizou-se a análise dos componentes principais (principal components - PC) e foi efetuada a análise fatorial (AF). Em virtude da obtenção de quatro fatores a partir da escala de Fatores Relacionados à Evasão e à Persistência em EaD, "Suporte tecnológico e de tutoria", "Características exógenas ao curso", "Características do aluno" e "Desenho do curso", relativos às variáveis historicamente ligadas ao abandono discente, foram testados diferentes modelos correlatos a cada um dos fatores extraídos.

\section{RESULTADOS}

A variável critério estudada no Modelo A foi a média das respostas dos participantes aos itens que compõem o fator "Suporte tecnológico e de tutoria", medida em termos das respostas dos participantes à escala de intensidade da influência das variáveis ligadas ao abandono e à permanência acadêmica. Encontram-se dispostas na Tabela 2 as correlações entre as variáveis, os coeficientes de regressão não padronizados $(B)$, os coeficientes de regressão padronizados $(\beta)$, a contribuição individual de cada variável $\left(S r^{2}\right)$, as médias das variáveis $(X)$, os desvios-padrão $(D P)$, a constante, a correlação entre todas as variáveis antecedentes com a variável critério - variância individual e compartilhada das variáveis antecedentes em relação à variável critério $\left(R^{2}\right)$, o $R^{2}$ ajustado (estimativa do $R^{2}$ da população) e a correlação entre a variável critério e as variáveis antecedentes $(r)$.

TABELA 2. Regressão múltipla padrão para o Modelo A

\begin{tabular}{|c|c|c|c|c|c|c|c|c|c|}
\hline Variável & Eva1 (VD) & Sexo & Idade & $\begin{array}{l}\text { Estado } \\
\text { civil }\end{array}$ & Família & Est1 ${ }^{* 1}$ & Est2 ${ }^{\star 2}$ & Est3 $^{\star 3}$ & Est4 ${ }^{* 4}$ \\
\hline Sexo & 0,02 & & & & & & & & \\
\hline Idade & $0,13^{*}$ & 0,03 & & & & & & & \\
\hline Estado civil & $0,15^{*}$ & $0,24^{*}$ & $0,42^{*}$ & & & & & & \\
\hline Família & $-0,00$ & $0,13^{*}$ & $-0,50$ & $-0,24$ & & & & & \\
\hline Est1 & $0,36^{*}$ & $-0,06$ & $0,14^{*}$ & $0,13^{*}$ & $-0,15$ & & & & \\
\hline Est2 & $0,28^{*}$ & 0,04 & $0,17^{*}$ & 0,03 & $-0,00$ & $0,36^{*}$ & & & \\
\hline Est3 & $0,39^{*}$ & $-0,32$ & 0,03 & $-0,13$ & $-0,23$ & $0,48^{*}$ & $0,15^{\star}$ & & \\
\hline Est4 & $0,31^{*}$ & $-0,34$ & $0,21^{*}$ & 0,03 & $-0,09$ & $0,60^{*}$ & $0,22^{*}$ & $0,42^{*}$ & \\
\hline$B$ & & 5,77 & 0,64 & 12,69 & 8,52 & $0,06^{*}$ & 0,57 & $1,74^{*}$ & 0,31 \\
\hline$\beta$ & & 0,09 & 0,02 & 0,19 & 0,13 & 0,04 & 0,17 & 0,36 & 0,11 \\
\hline$S r^{2}$ & & 0,00 & 0,00 & 0,01 & 0,00 & 0,00 & 0,01 & 0,05 & 0,00 \\
\hline$x$ & 38,55 & 1,52 & 3,47 & 1,63 & 1,41 & 74,29 & 46,56 & 11,05 & 43,76 \\
\hline$D P$ & 31,60 & 0,50 & 1,41 & 0,48 & 0,49 & 20,57 & 9,68 & 6,63 & 11,86 \\
\hline \multicolumn{2}{|c|}{ Constante $=-70,28$} & $R^{2}=0,27^{*}$ & \multicolumn{3}{|c|}{$R^{2}$ (ajustado $)=0,20^{*}$} & & & & \\
\hline
\end{tabular}

Nota. * $p<0,05$; Est1*1: Estratégias de Aprendizagem "Suporte tecnológico e de tutoria"; Est2 ${ }^{\star 2}$ : Estratégias de Aprendizagem "Características exógenas ao curso"; Est3*3: Estratégias de Aprendizagem "Características do aluno"; Est44: Estratégias de Aprendizagem "Desenho do curso"

$\mathrm{O}$ coeficiente de regressão múltipla $\mathrm{R}$ foi significativamente diferente de zero, $F(8,126)=3,99<0,001$, sendo considerados limites de confiança de $95 \%$. Duas variáveis antecedentes contribuíram significativamente para a explicação de suporte tecnológico e de tutoria, a saber: Est1 ( $\beta=0,04$ e IC de 95\%) e Est3 ( $\beta=0,36$ e IC de 95\%). Agrupadas, as oito variáveis iniciais explicam 27\% (20\% ajustado) da variabilidade de suporte tecnológico e de tutoria. Já em relação às variáveis que contribuíram significativamente para a explicação da variável critério, estas explicam cerca de $4 \%$ da variabilidade da mesma. 
De modo geral, os estudantes que relataram empregar com mais frequência as estratégias de aprendizagem de monitoramento da compreensão e de busca de ajuda interpessoal foram aqueles que mais consideraram o suporte tecnológico e de tutoria fornecido como relevante para sua continuidade no curso.

Para testagem do Modelo B, a variável critério investigada foi a média das respostas dos participantes aos itens que compõem o fator "Características exógenas ao curso", medida em termos das respostas dos participantes à escala de intensidade da influência das variáveis relacionadas ao abandono e à permanência acadêmica. $\mathrm{Na}$ Tabela 3, são apresentadas as correlações entre as variáveis, os coeficientes de regressão não padronizados $(B)$, os coeficientes de regressão padronizados $(\beta)$, a contribuição individual de cada variável $\left(S r^{2}\right)$, as médias das variáveis $(X)$, os desvios-padrão $(D P)$, a constante, a correlação entre todas as variáveis antecedentes com a variável critério - variância individual e compartilhada das variáveis antecedentes em relação à variável critério $\left(R^{2}\right)$, o $R^{2}$ ajustado (estimativa do $R^{2}$ da população) e a correlação entre a variável critério e as variáveis antecedentes $(r)$.

TABELA 3. Regressão múltipla padrão para o Modelo B

\begin{tabular}{|c|c|c|c|c|c|c|c|c|c|}
\hline Variável & Eva1 (VD) & Sexo & Idade & $\begin{array}{c}\text { Estado } \\
\text { civil }\end{array}$ & Família & Est1*1 & Est2*2 & Est3 ${ }^{\star 3}$ & Est4*4 \\
\hline Sexo & $-0,04$ & & & & & & & & \\
\hline Idade & 0,09 & 0,03 & & & & & & & \\
\hline Estado civil & 0,02 & $0,24^{*}$ & $0,42^{*}$ & & & & & & \\
\hline Família & $-0,17$ & $0,13^{*}$ & $-0,50$ & $-0,24$ & & & & & \\
\hline Est1 & $0,47^{*}$ & $-0,06$ & $0,14^{*}$ & 0,13 & $-0,15$ & & & & \\
\hline Est2 & $0,24^{*}$ & 0,04 & $0,17^{\star}$ & 0,03 & $-0,00$ & $0,36^{*}$ & & & \\
\hline Est3 & $0,44^{*}$ & $-0,32$ & 0,03 & $-0,13$ & $-0,23$ & $0,48^{*}$ & $0,15^{\star}$ & & \\
\hline Est4 & $0,28^{*}$ & $-0,34$ & $0,21^{*}$ & 0,03 & $-0,09$ & $0,60^{*}$ & $0,22^{*}$ & $0,42^{*}$ & \\
\hline$B$ & & 2,30 & $-0,22$ & $-0,28$ & $-3,25$ & $0,27^{*}$ & 0,18 & $0,81^{*}$ & $-0,04^{*}$ \\
\hline$\beta$ & & 0,06 & $-0,01$ & $-0,00$ & $-0,08$ & 0,31 & 0,09 & 0,28 & $-0,03$ \\
\hline $\mathrm{Sr}^{2}$ & & 0,00 & 0,00 & 0,00 & 0,00 & 0,03 & 0,00 & 0,03 & 0,00 \\
\hline$x$ & 12,92 & 1,54 & 3,48 & 1,61 & 1,43 & 74,71 & 46,44 & 11,22 & 43,94 \\
\hline DP & 18,61 & 0,50 & 1,41 & 0,48 & 0,49 & 20,91 & 9,69 & 6,58 & 11,93 \\
\hline \multicolumn{2}{|c|}{ Constante $=-21,16$} & $R^{2}=0,30^{*}$ & \multicolumn{3}{|c|}{$R^{2}$ (ajustado) $=0,23$ * } & $r=0,54$ * & & & \\
\hline
\end{tabular}

Nota. * $p<0,05$; Est1*1: Estratégias de Aprendizagem "Suporte tecnológico e de tutoria"; Est2*2: Estratégias de Aprendizagem "Características exógenas ao curso"; Est3*3: Estratégias de Aprendizagem "Características do aluno"; Est4*4:Estratégias de Aprendizagem "Desenho do curso"

Foi significativamente diferente de zero o coeficiente de regressão múltipla $R, F(8,126)=4,47<0,001$, sendo considerados limites de confiança de $95 \%$. Três variáveis antecedentes contribuíram significativamente para a explicação de características exógenas ao curso, a saber: Est1 ( $\beta=0,31$ e IC de 95\%), Est3 ( $\beta=0,28$ e IC de $95 \%)$ e Est4 ( $\beta=-0,03$ e IC de 95\%). Agrupadas, as oito variáveis iniciais explicam $30 \%$ ( $23 \%$ ajustado) da variabilidade de características exógenas ao curso. As variáveis que contribuíram significativamente para a explicação da variável critério explicam cerca de $6,2 \%$ da variabilidade de características exógenas ao curso.

Em suma, os discentes que consideraram as variáveis relativas às características exógenas ao curso como sendo de considerável importância para a não permanência deles no evento instrucional foram aqueles que afirmaram recorrer repetidas vezes às estratégias de monitoramento da compreensão, à busca de ajuda interpessoal e às estratégias cognitivo-comportamentais.

No Modelo C testado, a variável critério estabelecida foi a média das respostas dos participantes aos itens que compõem o fator "Características do aluno", medida em termos das respostas dos participantes à escala de intensidade da influência das variáveis relacionadas ao abandono e à permanência acadêmica. $\mathrm{Na}$ Tabela 4, encontram-se descritas as correlações entre as variáveis, os coeficientes de regressão não padronizados $(B)$, os coeficientes de regressão padronizados $(\beta)$, a contribuição individual de cada variável $\left(S r^{2}\right)$, as médias das variáveis $(X)$, os desvios-padrão $(D P)$, a constante, a correlação entre todas as variáveis antecedentes com a variável critério - variância individual e compartilhada das variáveis antecedentes em relação à variável critério $\left(R^{2}\right)$, o $R^{2}$ ajustado (estimativa do $R^{2}$ da população) e a correlação entre a variável critério e as variáveis antecedentes $(r)$. 
TABELA 4. Regressão múltipla padrão para o Modelo C

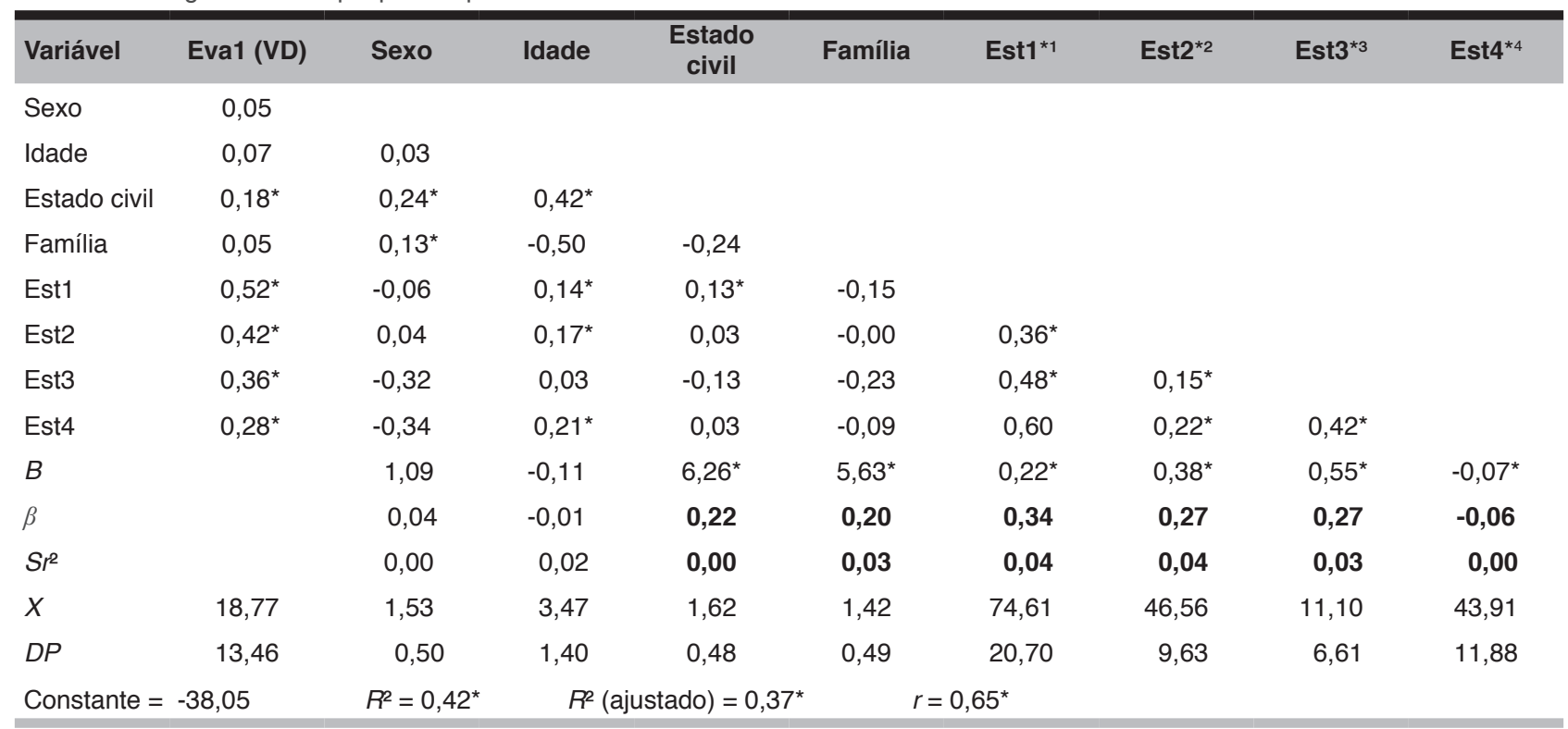

Nota. $p<0,05$; Est1*1: Estratégias de Aprendizagem "Suporte tecnológico e de tutoria"; Est2*2: Estratégias de Aprendizagem "Características exógenas ao curso"; Est3*3: Estratégias de Aprendizagem "Características do aluno"; Est4*4:Estratégias de Aprendizagem "Desenho do curso"

O coeficiente de regressão múltipla $\mathrm{R}$ foi significativamente diferente de zero, $\mathrm{F}(8,126)=7,99<0,001$, sendo considerados limites de confiança de $95 \%$. As variáveis antecedentes que contribuíram significativamente para a explicação de características do aluno foram: Composição familiar ( $\beta=0,20$ e IC de $95 \%)$, Estado civil ( $\beta=0,22$ e IC de 95\%), Est1 ( $\beta=0,34$ e IC de 95\%), Est2 ( $\beta=0,27$ e IC de 95\%), Est3 ( $\beta=0,27$ e IC de 95\%) e Est4 ( $\beta=-0,06$ e IC de 95\%). Agrupadas, as oito variáveis iniciais explicam 42\% (37\% ajustado) da variabilidade de características do aluno. As variáveis que contribuíram significativamente para a explicação da variável critério explicam cerca de $13,6 \%$ da variabilidade de características do aluno.

Em síntese, os alunos que fizeram uso recorrente das estratégias autorregulatórias, de monitoramento da compreensão, de busca de ajuda interpessoal e cognitivo-comportamentais ao longo do evento instrucional foram os mesmos que consideraram as características pessoais do alunado como interferentes sobre a decisão de abandonar o evento.

Para o Modelo D, a variável critério estimada foi a média das respostas dos participantes aos itens que compõem o fator "Desenho do curso", medida em termos das respostas dos participantes à escala de intensidade da influência das variáveis relacionadas ao abandono e à permanência acadêmica. São apresentadas na Tabela 5 as correlações entre as variáveis, os coeficientes de regressão não padronizados $(B)$, os coeficientes de regressão padronizados $(\beta)$, a contribuição individual de cada variável $\left(S r^{2}\right)$, as médias das variáveis $(X)$, os desvios-padrão $(D P)$, a constante, a correlação entre todas as variáveis antecedentes com a variável critério - variância individual e compartilhada das variáveis antecedentes em relação à variável critério $\left(R^{2}\right)$, o $R^{2}$ ajustado (estimativa do $R^{2}$ da população) e a correlação entre a variável critério e as variáveis antecedentes $(r)$. 
TABELA 5. Regressão múltipla padrão para o Modelo D

\begin{tabular}{|c|c|c|c|c|c|c|c|c|c|}
\hline Variável & Eva1 (VD) & Sexo & Idade & $\begin{array}{l}\text { Estado } \\
\text { civil }\end{array}$ & Família & Est ${ }^{* 1}$ & Est2 ${ }^{\star 2}$ & Est $^{\star 3}$ & Est4 $^{\star 4}$ \\
\hline Sexo & 0,09 & & & & & & & & \\
\hline Idade & $-0,00$ & 0,03 & & & & & & & \\
\hline Estado civil & $0,14^{*}$ & $0,24^{*}$ & $0,42^{*}$ & & & & & & \\
\hline Família & $-0,02$ & $0,13^{*}$ & $-0,50$ & $-0,24$ & & & & & \\
\hline Est1 & $0,37^{*}$ & $-0,06$ & $0,14^{*}$ & $0,13^{*}$ & $-0,15$ & & & & \\
\hline Est2 & $0,33^{*}$ & 0,04 & $0,17^{\star}$ & 0,03 & $-0,00$ & $0,36^{*}$ & & & \\
\hline Est3 & $0,27^{\star}$ & $-0,32$ & 0,03 & $-0,13$ & $-0,23$ & $0,48^{*}$ & $0,15^{*}$ & & \\
\hline Est4 & $0,23^{*}$ & $-0,34$ & $0,21^{*}$ & 0,03 & $-0,09$ & $0,60^{*}$ & $0,22^{*}$ & $0,42^{\star}$ & \\
\hline$B$ & & 2,92 & $-1,39$ & 3,63 & $-0,46$ & $0,07^{*}$ & $0,26^{*}$ & 0,28 & $0,05^{*}$ \\
\hline$\beta$ & & 0,14 & $-0,19$ & 0,17 & $-0,02$ & 0,15 & 0,25 & 0,19 & 0,07 \\
\hline$S r^{2}$ & & 0,01 & 0,01 & 0,01 & 0,00 & 0,00 & 0,03 & 0,01 & 0,00 \\
\hline$x$ & 8,14 & 1,53 & 3,47 & 1,62 & 1,42 & 74,61 & 46,56 & 11,10 & 43,91 \\
\hline$D P$ & 9,89 & 0,50 & 1,40 & 0,48 & 0,49 & 20,70 & 9,63 & 6,61 & 11,88 \\
\hline \multicolumn{2}{|c|}{ Constante $=-20,11$} & $R^{2}=0,24^{*}$ & & \multicolumn{2}{|c|}{$R^{2}$ (ajustado $)=0,17^{*}$} & $r=0,49^{*}$ & & & \\
\hline
\end{tabular}

Nota. * $p<0,05$; Est1*1: Estratégias de Aprendizagem "Suporte tecnológico e de tutoria"; Est2*2: Estratégias de Aprendizagem, 11, ;"Características exógenas ao curso"; Est3*3: Estratégias de Aprendizagem "Características do aluno"; Est4*4:Estratégias de Aprendizagem "Desenho do curso"

O coeficiente de regressão múltipla $R$ foi significativamente diferente de zero, $F(8,126)=3,43<0,001$, sendo considerados limites de confiança de $95 \%$. As variáveis antecedentes que contribuíram significativamente para a explicação de desenho do curso foram Est1 ( $\beta=0,15$ e IC de 95\%), Est2 ( $\beta=0,25$ e IC de 95\%) e Est4 ( $\beta=0,07$ e IC de 95\%). Agrupadas, as oito variáveis iniciais explicam 24\% (17\% ajustado) da variabilidade de desenho do curso. As variáveis que contribuíram significativamente para a explicação da variável critério explicam cerca de $5 \%$ de sua variabilidade.

Depreende-se que os discentes que relataram empregar com constância as estratégias autorregulatórias, de aprendizagem denominadas monitoramento da compreensão, e cognitivo-comportamentais foram aqueles que declararam ser vital, para a permanência do aprendiz no evento a distância, o desenho do curso realizado.

\section{DISCUSSÃO}

O modelo testado de avaliação de ações educacionais a distância foi composto por variáveis individuais e sociodemográficas, visando reconhecer possíveis relacionamentos com os fatores historicamente ligados à evasão e à persistência em EaD. Dessa feita, foram consideradas as seguintes variáveis antecedentes: média das respostas aos itens dos quatro fatores extraídos da ferramenta de Estratégias de aprendizagem e média das respostas aos itens da escala de dados sociodemográficos.

No Modelo $\mathrm{A}$, as variáveis que revelaram relação com fatores ligados à evasão e à persistência foram Monitoramento da compreensão $(\beta=0,04)$ e Busca de ajuda interpessoal $(\beta=0,36)$. A variância compartilhada e individual das variáveis antecedentes agrupadas, em relação à variável critério, foi de $R^{2}=36 \%$. Os participantes que perceberam considerável interferência da variável "Suporte tecnológico e de tutoria" sobre a decisão de permanecer ou não no evento instrucional foram aqueles que empregaram com mais frequência as estratégias de "Monitoramento da compreensão" e "Busca de ajuda interpessoal". Aqueles que empregam com mais frequência as estratégias de aprendizagem descritas anteriormente também consideram o "Suporte tecnológico e de tutoria" fornecido como o aspecto mais relevante para sua continuidade no curso. Tal relação é razoável quando se considera a relevância que o apoio prestado aos discentes pelos profissionais e a instituição educativa teria para os indivíduos que mais recorrem à obtenção de orientações e ao auxílio de seus pares, a fim de mitigar dúvidas sobre os conteúdos transmitidos. Ou seja, o emprego exitoso da estratégia de procura de ajuda interpessoal dependeria em grande parte da qualidade do suporte ofertado e dos recursos tecnológicos subsidiários a ele. Ademais, em situações de aprendizagem nas quais o aprendiz torna-se o principal responsável pelo ganho 
efetivo de conhecimento, é esperado e desejável o desenvolvimento de habilidades que o auxiliem a inspecionar os processos cognitivos que geram tal ganho.

Para estudantes a distância, o conjunto de agentes e instrumentais envolvidos no desenvolvimento das ações educacionais implementadas não atua apenas como fragmento acessório e secundário, mas subsidia de forma fundamental toda ação ou decisão a ser tomada em cenários de EaD (Almeida, 2007; Holder, 2007; Sales, 2009; Vargas, 2004). Torna-se imprescindível cuidar para que o corpo discente tenha acesso de qualidade aos aspectos operacionais e de suporte ao longo das ações instrutivas, pois se observa que os níveis de abandono discente são influenciados por fatores ligados a qualidade e quantidade de apoio fornecido ao aprendiz, além do tipo e dos meios selecionados para estabelecer contato com eles (Abbad, Carvalho \& Zerbini, 2006; Xenos et al., 2002; Walter, 2006).

As variáveis no Modelo B que apresentaram relação com características exógenas ao curso na ordem de magnitude das contribuições individuais foram Monitoramento da compreensão ( $\beta=0,31)$, Busca de ajuda interpessoal $(\beta=0,28)$ e Estratégias cognitivo-comportamentais $(\beta=-0,03)$. As variâncias compartilhada e individual das variáveis antecedentes agrupadas, em relação à variável critério, foi de $R^{2}=30 \%$. Tais dados indicam que os discentes que definiram as variáveis ambientais como as mais influentes na decisão de dar continuidade ou não ao curso foram os mesmos cujos padrões de uso de estratégias voltadas ao gerenciamento dos processos de ensino-aprendizagem, à procura por ajuda externa e à estruturação cognitiva dos conteúdos acadêmicos se mostram mais elevados. Para os discentes que consideram a variável ambiental como a mais influente para a decisão de dar continuidade ou não ao curso, as estratégias empregadas maciçamente são as de monitoramento da compreensão, busca de ajuda interpessoal e estratégias cognitivo-comportamentais. Tendo em vista que os aprendizes a distância estão sujeitos a um maior número de distrações e respondem por uma extensa gama de afazeres, é possível que, para tais indivíduos, cujas intempéries situacionais podem dificultar, sobremaneira, a realização de uma ação educativa em $\mathrm{EaD}$, o auxílio prestado por terceiros figure como elemento-chave para uma resolução de problemas de aprendizagem mais imediata e diretiva. Além disso, na presença de eventos concorrentes, não é possível afirmar que o aprendiz se sentirá disperso ou desmotivado, mas certamente deverá dedicar mais esforços a fim de que seu processo de aprendizagem seja eficaz. Nesse sentido, as estratégias voltadas à organização e ao controle dos fenômenos psíquicos que subsidiam o aprender atuarão como prestimosos recursos para superação de desatenções ambientais.

$\mathrm{Na}$ literatura, as variáveis relacionadas ao meio circundante do aluno a distância aparecem diretamente ligadas à interrupção dos cursos, ou seja, quanto mais os alunos percebem tais elementos como dificultadores de sua permanência, mais chances eles terão de se evadirem (Almeida, 2007; Sales, 2009; Silva \& Tomaz, 2006; Walter, 2006; Yukselturk \& Inan, 2006). Em modelos testados, variáveis dessa natureza foram consideradas preditoras de evasão. A influência desse conjunto de fatores sobre a permanência estudantil é quase uma unanimidade entre os pesquisadores do campo. Contextualizando o resultado obtido ao perfil da amostra analisada, constata-se que a maioria dos participantes se declarou mantenedora de relação matrimonial estável, com filhos, e executores de atividades profissionais paralelas. Logo, é possível concluir que se trata de um conjunto de pessoas que respondem por inúmeros compromissos e, consequentemente, enfrentam sérias adversidades contextuais. Destaca-se, nesse ponto, a influência dos aspectos autogerenciadores da informação/ compreensão e da resolução proativa de conflitos de aprendizagem para a não desistência do aluno a distância. Portanto, ressalta-se, mais uma vez, a importância das estratégias de monitoramento da compreensão para os aprendizes em EaD. Tais habilidades revelam-se decisórias em momentos nos quais o compromisso do indivíduo para com o curso é prejudicado pelo aparecimento de contratempos circunstanciais. Estar atento ao progresso e ao êxito de suas atividades acadêmicas garante ao aprendiz maiores chances de identificar lapsos de comprometimento e, com isso, prevenir possíveis desistências. A literatura pontua o papel preponderante das competências voltadas ao controle eficiente da informação e dos processos de pensamento para o sucesso acadêmico do aluno (Badia \& Monereo, 2010; Oliveira, Boruchovitch \& Santos, 2009).

$\mathrm{Na}$ testagem do Modelo $\mathrm{C}$, as variáveis que apresentaram relação com características do aluno, segundo a ordem de magnitude das contribuições individuais foram Monitoramento da compreensão $(\beta=0,34)$, Estratégias autorregulatórias $(\beta=0,27)$, Busca de ajuda interpessoal $(\beta=0,27)$, Estado civil $(\beta=0,22)$, Composição familiar $(\beta=0,20)$ e Estratégias cognitivo-comportamentais $(\beta=-0,06)$. As variâncias compartilhada e individual das variáveis antecedentes agrupadas, em relação à variável critério, foi de $R^{2}=42 \%$. Tais dados sinalizam que, para os alunos que empregam predominantemente estratégias de aprendizagem voltadas à autogestão dos 
processos de aquisição de aprendizagem, ao controle do aspecto emocional, à solicitação por ajuda externa e ao armazenamento cognitivo dos objetos de estudo, os seus atributos psicológicos são tidos como mais importantes para a decisão de interromper a ação educativa empreendida. As variáveis sociodemográficas correlatas à constituição familiar (com ou sem filhos) e à condição marital (solteiro ou casado) também mostraram relação com a variável critério.

Considerando a própria definição teórica apresentada pelas estratégias de aprendizagem referidas, constatase que elas decorrem de um complexo conjunto de capacidades cognitivas desenvolvidas pelo sujeito ao longo de sua vida. Portanto, sendo derivadas de características pessoais do indivíduo que aprende, é razoável que estudantes que servem-se delas também compreendam seus atributos psíquicos como relevantes para a execução do curso e sua finalização. Depreende-se também que, para os participantes casados e com filhos, os atributos internos do sujeito que aprende são de grande relevância para sua permanência no curso. É provável que para tais indivíduos esse específico arranjo familiar (presença de filhos e cônjuge) implique em numerosos compromissos que, para não dificultarem a continuidade da ação instrucional, dependerão de suas características pessoais - em termos de persistência e comprometimento com suas incumbências acadêmicas.

Pesquisas revelam que as características internas do alunado são importantes para o entendimento da presença de tais indivíduos ao longo das ações instrucionais. Nesse sentido, tais variáveis vêm sendo amplamente discutidas e tendo seu papel de facilitadores à permanência estudantil em EaD esquadrinhado (Brauer, 2005; Silva \& Tomaz, 2006; Xenos et al., 2002; Walter, 2006; Wang et al., 2003). Assim, práticas relativas a análises de necessidades de treinamento poderiam beneficiar a adequação do evento ao seu público alvo, uma vez que orientariam todas as ações instrucionais de planejamento e ministração com base nos predicados discentes (Abbad, 2009; Borges-Andrade, 2006; Sales, 2009).

Neste estudo, as variáveis sociodemográficas relativas à composição familiar e ao estado civil tiveram contribuição significativa na explicação do fator "Características do aluno". É cabível que estudantes com arranjos pessoais mais complexos e requerentes de maior dedicação (como quando na presença de filhos e companheiros conjugais) venham a valorizar e presumir que o abandono acadêmico não se efetua graças as suas competências e disposições de caráter interno. Tendo em vista que inúmeras pesquisas se detêm sobre os dados sociodemográficos da clientela em EaD, é recomendável que estas e outras variáveis dessa categoria continuem a ser exploradas para que maior consistência teórica seja atribuída a esse tema (Brauer, 2005; Sales, 2009; Vargas, 2004; Walter, 2006).

No Modelo $\mathrm{D}$, as variáveis que apresentaram relação com fatores ligados à evasão e à persistência foram Monitoramento da compreensão $(\beta=-0,15)$, Estratégias autorregulatórias $(\beta=0,25)$ e Estratégias cognitivocomportamentais $(\beta=0,07)$. As variâncias compartilhada e individual das variáveis antecedentes agrupadas, em relação à variável critério, foi de $R^{2}=24 \%$. Os participantes que empregaram com mais frequência as estratégias autorregulatórias, de aprendizagem monitoramento da compreensão e cognitivo-comportamentais foram aqueles para quem a variável desenho do curso exerceu forte atuação sobre a decisão de permanecer ou não no evento instrucional.

Achados da literatura apontam para a relevância da estruturação instrucional para a saída ou permanência do estudante em contextos de EaD. Segundo tais estudos, o fenômeno do abandono estudantil estaria intrinsecamente ligado a inadequações na forma como a ação educativa é delineada e ministrada. Nesse caso, mencionam-se desajustes quanto ao estabelecimento de objetivos instrucionais, à escolha de estratégias de ensino, à complexidade dos conteúdos de aprendizagem, à natureza dos exercícios propostos, à qualidade das atividades face a face programadas para momentos específicos do curso, ao volume de trabalhos requeridos, entre outros (Silva \& Tomaz, 2006; Xenos et al., 2002; Walter, 2006). Tendo em vista que a literatura em EaD define a estrutura da ação educativa como elemento medular para o bom desempenho acadêmico, é cabível considerar que indivíduos que devotam elevada importância ao papel desempenhado pelas propriedades do curso deverão ser aqueles que fazem dos recursos voltados ao controle do processo de aprendizagem e do aspecto emocional dispositivos habituais para sua permanência nele. Ou seja, em determinadas circunstâncias, as estratégias primárias e autorregulatórias parecem atuar no sentido de amparar o discente frente a possíveis falhas de estruturação do evento educacional.

Esses resultados sinalizam, portanto, uma relação entre fatores ligados à ocorrência de evasão em contextos de $\mathrm{EaD}$ e estratégias de aprendizagem. Tais dados guardam correspondência e apoio nos resultados empíricos 
obtidos por estudos anteriores, ou seja, atesta-se a significância do emprego de um variado repertório de estratégias de aprendizagem para a excelência acadêmica (Badia \& Monereo, 2010; Oliveira et al., 2009).

Os modelos de predição testados forneceram indícios de que quanto mais forem aplicadas estratégias de aprendizagem específicas, maiores serão as chances de o corpo discente perceber um conjunto específico de variáveis como muito influentes sobre a permanência ou saída deles de seus cursos. Deve-se averiguar o grau em que todas essas variáveis relacionam-se com os elementos ligados à desistência acadêmica nas diferentes modalidades educacionais. A depender da natureza do evento instrucional, se poderia reconhecer distintos padrões de uso de estratégias de aprendizagem e, consequentemente, diferentes fatores preditivos.

As limitações desse estudo relacionam-se principalmente ao baixo índice de devolução dos questionários, ao pequeno número da amostra e à grande quantidade de cursos considerados. Futuras pesquisas em ambientes escolares, especificamente do nível superior de ensino, poderão ratificar ou retificar tais dificuldades e aprimorar os meios de coleta de dados. Apesar das limitações verificadas, são gerados subsídios que podem auxiliar no aprimoramento de programas instrucionais a distância.

\section{REFERÊNCIAS}

Abbad, G. S. (2007). Educação a distância: o estado da arte e o futuro necessário. Revista do Serviço Público, 58, 100-110.

Abbad, G. S. (2009). Avaliação de necessidades e avaliação de impactos de programas de treinamento presenciais e a distância em organizações e trabalho. (Relatório de Pesquisa). Recuperado do site da Universidade de Brasília: file:///C:/Users/Daniele/Documents/Downloads/Analise_de_Necessidades_e_Avaliacao_de_Impactos.Projeto_PQ_-_inicio_2010.pdf

Abbad, G., Carvalho, R. S., \& Zerbini, T. (2006). Evasão em curso via Internet: Explorando variáveis explicativas. RAE-eletrônica, 5(2). doi: 10.1590/S1676-56482006000200008

Abreu-e-Lima, D. M., \& Alves, M. N. (2011). O feedback e sua importância no processo de tutoria a distância. Pro-Posições, 22(2), 189-205. doi: 10.1590/S0103-73072011000200013

Almeida, O. C. S. (2007). Evasão em cursos a distância: Validação de instrumento, fatores influenciadores e cronologia da desistência (Dissertação de mestrado). Recuperado de http://bdtd.bce.unb.br/tedesimplificado/tde_arquivos/65/TDE-2007-1026T170707Z-1970/Publico/Dissert_Onilia\%20Cristina.pdf

Alves, L. (2011). Educação a distância: Conceitos e história no Brasil e no mundo. Revista Brasileira de Aprendizagem Aberta e a Distância, 10, 83-92.

Associação Brasileira de Educação a Distância (2012). Censo EaD Brasil 2012. Recuperado de http://www.abed.org.br/censoead/ censoEAD.BR_2012_pt.pdf

Badia, A., \& Monereo, C. (2010). Ensino e aprendizagem de estratégias de aprendizagem em ambientes virtuais. In C. Coll \& C. Monereo (Orgs.), Psicologia da educação virtual - Aprender e ensinar com as tecnologias da informação e da comunicação (pp. 311-38). Porto Alegre: Artmed.

Borges-Andrade, J. E. (2006). Avaliação integrada e somativa em TD\&E. In J. E. Borges-Andrade, G. Abbad \& L. Mourão (Orgs.), Treinamento, desenvolvimento e educação em organizações e trabalho: Fundamentos para a gestão de pessoas (pp. 343358). Porto Alegre: Artmed.

Brauer, S. (2005). Avaliação de um curso a distância: Valor instrumental do treinamento, barreiras pessoais à conclusão e evasão (Dissertação de mestrado não publicada), Instituto de Psicologia da Universidade de Brasília, Brasília.

Carvalho, R. S., \& Abbad, G. (2006). Avaliação de treinamento a distância: Reação, suporte à transferência e impactos no trabaIho. Revista de Administração Contemporânea, 10(1), 95-116. doi: 10.1590/S1415-65552006000100006

Castro, M. N. M., \& Ferreira, L. D. V. (2006). TD\&E a distância: Múltiplas mídias e clientelas. In J. E. Borges-Andrade, G. Abbad, L. Mourão (Orgs.), Treinamento, desenvolvimento e educação em organizações e trabalho: fundamentos para a gestão de pessoas (pp. 322-339). Porto Alegre: Artmed.

Deimann, M., \& Bastiaens, T. (2010). The role of volition in distance education: An exploration of its capacities. International Review of Research in Open and Distance Learning, 11(1), 1-16.

França, G. (2009). Os ambientes de aprendizagem na época de hipermídia e da Educação a distância. Perspectivas em Ciência da Informação, 14(1), 55-65. doi: 10.1590/S1413-99362009000100005

Iglesias, M., \& Salgado, J. F. (2012). Effectiveness of occupational training through videoconferencing: Comparison with classroom training and individual differences. Revista de Psicología del Trabajo y de las Organizaciones, 28(3), 183-188. doi: $10.5093 / \operatorname{tr} 2012 \mathrm{a} 15$ 
Holder, B. (2007). An investigation of hope, academics, environment, and motivation as predictors of persistence in higher education online programs. Internet and Higher Education, 10, 245-260. doi: 10.1016/j.iheduc.2007.08.002

Lee, H. S., \& Anderson, J. R. (2013). Student learning: What has instruction got to do with it? Annual Review of Psychology, 64(3), 1-25. doi: 10.1146/annurev-psych-113011-143833

Martins, L. B. (2012). Aprendizagem em ações educacionais a distância: Fatores influentes no desempenho acadêmico de universitário (Dissertação de mestrado). Recuperado de http://www.ffclrp.usp.br/imagens_defesas/18_12_2012__14_43_01_61. pdf

Meneses, P. P. M., Abbad, G., Zerbini, T., \& Lacerda, E. (2006). Medidas de características da clientela em avaliação de TD\&E. In J. E. Borges-Andrade, G. Abbad \& L. Mourão (Orgs.), Treinamento, desenvolvimento e educação em organizações e trabaIho: fundamentos para a gestão de pessoas (pp. 422- 442). Porto Alegre: Artmed.

Meneses, P. P. M., Zerbini, T., \& Abbad, G. (2010). Manual de treinamento organizacional. Porto Alegre: Artmed.

Ngoma, P. S., Simwanza, A., \& Makukna, C. K. (2004). Investigating the drop out problem amongst university extension studies learners in Zambia. Third Pan- Commonwealth Forum on Open Learning, Dunedin, New Zealand. Recuperado de http:// www.col.org/pcf3/Papers/PDFs/Ngoma_Simwanza_Makunka.pdf

Oliveira, K. L., Boruchovitch, E., \& Santos, A. A. A. (2009). Estratégias de aprendizagem e desempenho acadêmico: Evidências de validade. Psicologia: Teoria e Pesquisa, 25(4), 531-536. doi: 10.1590/S0102-37722009000400008

Oliveira, E. A., \& Tedesco, P. (2010). I-collaboration: Um modelo de colaboração inteligente personalizada para ambientes de EAD. Revista Brasileira de Informática na Educação, 18(1), 17-31. doi: 10.5753/RBIE.2010.18.01.17

Pacheco, A. S. V., Rissi, M., Nakayama, M. K., Silveira, R. A., \& Spanhol, F. J. (2010). A desistência de estudantes de um curso na modalidade a distância voltado para adolescentes. Revista Novas Tecnologias na Educação, 8(3), 1-10.

Romero, M., \& Barberà, E. (2011). Quality of learners' time and learning performance beyond quantitative time-on-task. The International Review Of Research In Open And Distance Learning, 12(5), 125-137.

Sales, P. A. O. (2009). Evasão em cursos a distância: Motivos relacionados às características do curso, do aluno e do contexto de estudo (Dissertação de mestrado). Recuperado de http://repositorio.unb.br/handle/10482/8440

Silva, D. R., \& Tomaz, J. B. C. (2006). Por que a evasão? Ceará: Escola de Saúde Pública do Ceará.

Simpson, O. (2013). O futuro da educação a distância: Que fatores afetarão como a educação a distância se desenvolverá no futuro? Revista Brasileira de Aprendizagem Aberta e a Distância, 12, 149-162.

Siqueira, K. F. (2009). Alguns estudos sobre evasão e persistência de estudantes. Eccos - Revista Científica, 11(1), $247-264$.

Tabachnick, B. G., \& Fidell, L. S. (2001). Using multivariate statistics. New York: Harper-Collins College Publishers.

Umekawa, E. E. R. (2014). Preditores de fatores relacionados à evasão e à persistência discente em ações educacionais a distância (Dissertação de mestrado). Recuperado de http://www.teses.usp.br/teses/disponiveis/59/59137/tde-23032014115420/pt-br.php

Vargas, M. R. M. (2004). Barreiras à implantação de programas de educação e treinamento a distância (Tese de doutorado não publicada). Universidade de Brasília, Brasília.

Xenos, M., Pierrakeas, C., \& Pintelas, P. (2002). A survey on student dropout rates and dropout causes concerning the students in the Course of Informatics of the Hellenic Open University. Computers \& Education, 39, 361-377. doi: 10.1016/S03601315(02)00072-6

Walter, A. M. (2006). Variáveis preditoras de evasão em cursos a distância (Dissertação de mestrado). Recuperado de http://repositorio.unb.br/bitstream/10482/6532/1/2006_Amanda\%20Moura\%20Walter.pdf

Wang, G., Foucar-Szocki, D., Griffen, O., O'Connor, C., \& Sceiford, E. (2003). Departure, abandonment, and dropout of e-learning: Dilemma and solutions. (Relatório de Pesquisa). Recuperado de http://www.titaylor.net/research/DepartureAbandonment-Dropout-of-Elearning-Dilemma-and-Solutions-JamesMadison-University-2003.pdf

Warr, P., \& Allan, C. (1998). Learning strategies and occupational training. Internacional Review of Industrial and Organizational Psychology, 13, 83-121.

Yukselturk, E., \& Inan, F. A. (2006). Examining the factors affecting student dropout in an online certificate program. Turkish Online Journal of Distance Education-TOJDE, 7(3), 76-88.

Zerbini, T. (2007). Avaliação da transferência de treinamento em curso a distância (Tese de doutorado). Recuperado de http:// bdtd.bce.unb.br/tedesimplificado/tde_arquivos/27/TDE-2007-05-18T152226Z-1049/Publico/Tese_Thais\%20Zerbini.pdf

Zerbini, T., \& Abbad, G. (2010). Aprendizagem induzida pela instrução em contexto de organizações e trabalho: uma análise crítica da literatura. Cadernos de Psicologia Social do Trabalho, 13(2), 177-193. doi: 10.11606/issn.1981-0490.v13i2p177-193 